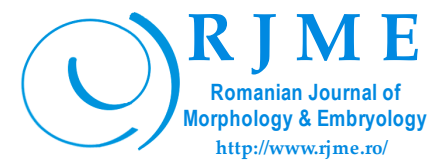

\title{
Bifid mandibular canal - a case report
}

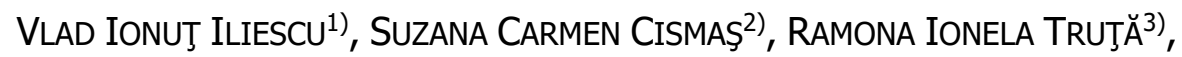

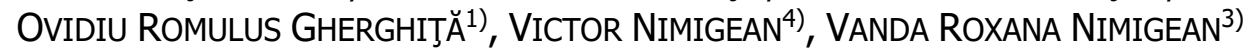

\author{
1)PhD Student, Faculty of Dental Medicine, Carol Davila University of Medicine and Pharmacy, Bucharest, Romania \\ 2) Department of Modern Languages, University of Agronomic Sciences and Veterinary Medicine, Bucharest, Romania \\ 3) Discipline of Oral Rehabilitation, Faculty of Dental Medicine, Carol Davila University of Medicine and Pharmacy, Bucharest, \\ Romania \\ 4)Discipline of Anatomy, Faculty of Dental Medicine, Carol Davila University of Medicine and Pharmacy, Bucharest, Romania
}

\begin{abstract}
One of the most common anatomical variations of the mandibular canal is the bifid mandibular canal (BMC), more frequently unilateral and rarely bilateral, often located at the level of the posterior mandible; according to literature, this anatomical variation presents several morphological types. The presence of the BMC must be considered prior to anesthesia and surgery performed on the ramus of the mandible (osteotomies) and on the posterior mandible (dentoalveolar surgery procedures). This study presents a clinical case of unilateral BMC on the left side, the buccolingual type, lingual variant, a rare anatomical variation illustrated radiographically in a 27 -year-old male adult.
\end{abstract}

Keywords: mandibular canal, anatomical variations, panoramic radiography, СBCT scan.

\section{口 Introduction}

The mandibular canal (MC) is formed by merging three primary canals, the contents of which are intended for innervation and vascularization of different groups of teeth: a canal for incisors, a canal for temporary molars and one for permanent molars. This theory would explain the appearance of the bifid (double) or triple MC, and of the secondary MCs, due to the incomplete fusion of the three primary canals [1].

As reported in certain data from the literature, the bifid mandibular canal (BMC) is an anatomical variation with an irregular percentage range, occurring in $2 \%$ of cases as some authors state [2], and reaching up to $65 \%$ of cases, respectively, according to others, who have shown that such anatomical variation can be unilateral and rarely bilateral [3]. However, studies performed on panoramic radiographs (orthopantomography - OPG) showed low frequency for BMCs, less than $10 \%$, but the frequency was higher in studies performed on cone-beam computed tomography (CBCT) scans, up to $66.7 \%$ of the analyzed cases, and in $46.5 \%$ of them BMCs were found to be bilateral [4].

Topographically, BMC is most commonly located in the mandibular retromolar area, $40 \%$ of cases, in the ramus of the mandible in $27.7 \%$ of cases, and in the molar area in $17.1 \%$ of cases [4].

The BMCs may have an independent origin at the level of the mandibular foramen or may detach from the main canal (the MC) located inside the ramus of the mandible, and may contain vessels and nerves $[5,6]$.

This type of anatomical variation can be visualized radiologically by OPG and especially by the CBCT scan, a procedure through which the narrow accessory canals can be observed, thus constituting an important and necessary investigation for the planning of dental treatment. Through multiplanar reformation (MPR), CBCT technology proved to be an indispensable diagnostic tool in identifying BMCs. $\mathrm{BMC}$ existence without clinical acknowledgement may complicate the surgery procedures performed for the third molar, the mandibular reconstructive surgery, and the mandibular sagittal osteotomies performed in orthognathic surgery [4, 7-11].

\section{Aim}

This clinical case report presents a unilateral BMC, initially visualized by panoramic radiography, and then confirmed by CBCT.

\section{도 Case presentation}

The male patient, 27 years old, clinically healthy, without general ailments, presented in a private dental clinic with spontaneous, severe, lingering pain, exacerbated by thermal agents; the pain was located at the level of the left mandibular third molar. On clinical examination, an occlusal composite restoration with distal secondary caries was found.

The diagnosis established according to dental history and clinical examination was irreversible pulpitis. The recommended treatment was root canal treatment, and the patient agreed, signing the informed consent.

According to the medical history, the patient had undergone dental treatment 37 months before (decay removal and composite restoration in the third left mandibular molar, tooth No. 38); he reported that, despite anesthesia, he felt pain during the preparation of the cavity for future coronal restoration. For this reason, prior to performing the locoregional anesthesia for the root canal treatment, a panoramic

This is an open-access article distributed under the terms of a Creative Commons Attribution-NonCommercial-ShareAlike 4.0 International Public License, which permits unrestricted use, adaptation, distribution and reproduction in any medium, non-commercially, provided the new creations are licensed under identical terms as the original work and the original work is properly cited. 
radiography was requested. On this radiography, we identified a unilateral BMC, on the left side (Figure 1).

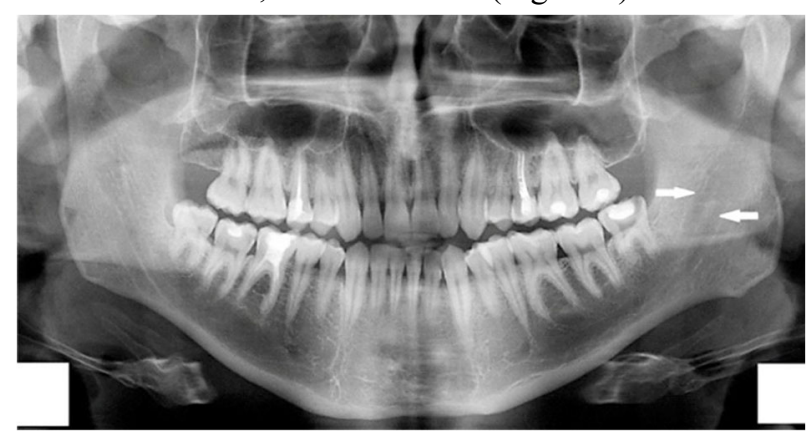

Figure 1 - OPG: left bifid mandibular canal (white arrows). OPG: Orthopantomography.

For an accurate diagnosis, a CBCT scan was taken. This examination confirmed the presence of the unilateral BMC on the left side (Figures 2-4).

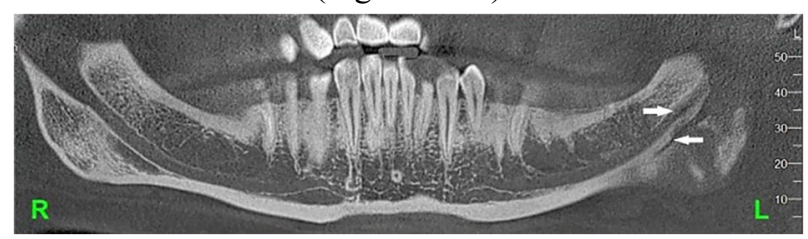

Figure 2 - Reformatted panoramic image of CBCT with identification of the left bifid mandibular canal (white arrows). CBCT: Cone-beam computed tomography; L: Left; R: Right.

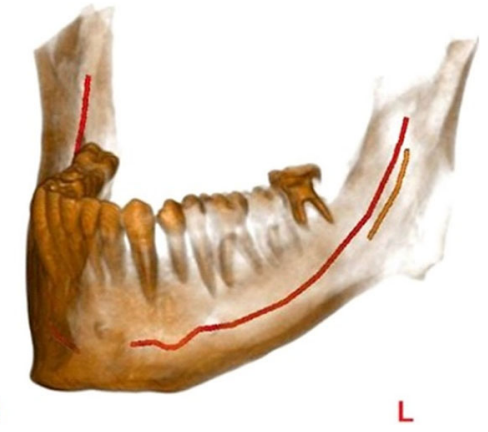

Figure 3-CBCT: 3D image with identification of the left bifid mandibular canal. 3D: Three-dimensional; CBCT: Cone-beam computed tomography; L: Left; R: Right.

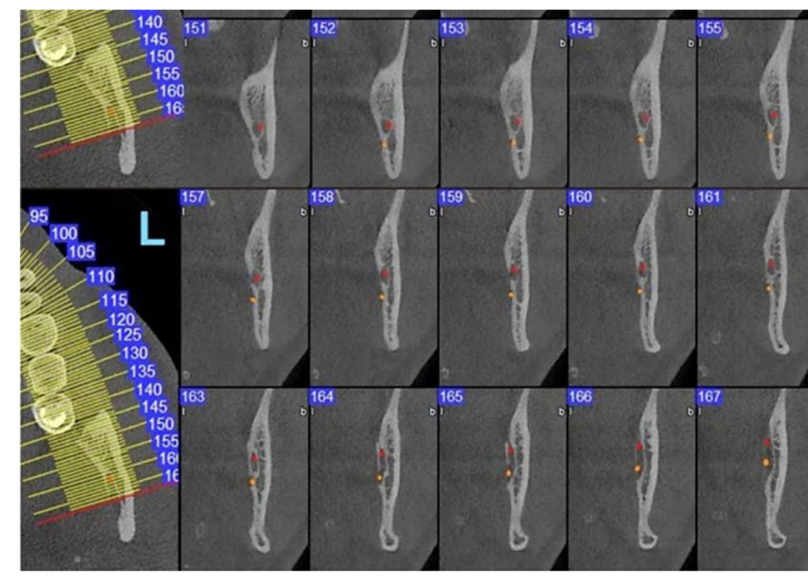

Figure 4 - CBCT sequential cross-sectional images: left bifid mandibular canal (buccolingual type, lingual variant). Red: mandibular canal; Orange: buccolingual canal, lingual variant. CBCT: Cone-beam computed tomography; L: Left.
Due to the definite presence of this anatomical variation, we decided to perform the Gow-Gates technique for the anesthesia of the inferior alveolar nerve; as a result, the root canal treatment of the left third mandibular molar was performed without pain, the patient finally declaring that the therapeutic procedure was comfortable and painless.

\section{吕 Discussions}

Although the literature shows multiple variations on the internal root morphology of the mandibular wisdom teeth [12], in this clinical situation the endodontic treatment was facilitated by the existence of three root canals, one located in the distal root, and two located in the mesial root, an internal root morphology which is characteristic of the first two molars.

In our case study the accessory MC was located at the level of the ramus of the mandible, lingual and inferior to the MC.

Taking into account the classification by Naitoh et al. (2009) [13], performed according to data obtained by CBCT images, this anatomical variant falls into type IV BMCs: buccolingual canals, lingual variant, originating in the lingual wall of $\mathrm{MC}$, a rare variant, present in $1.8 \%$ of cases, according to Naitoh et al. (2009) [13], in 9.7\% of cases, as stated by Okumuş \& Dumlu (2019) [14], in 10.6\% of cases, in accordance with Kuribayashi et al. $(2010)[6,15]$ and in $14.3 \%(4.76 \%$ buccal canal and $9.5 \%$ lingual canal) of cases, as reported by Nithya \& Aswath (2020) [8].

In one of the two case reports presented by Mizbah et al. (2012) [3], the authors described a buccolingual accessory canal that extended lingually to the roots of the third molar and was susceptible to injury during the surgical removal of this tooth.

According to the data provided by the CBCT multiplanar reformatted images used in this study, the length of the accessory MC was $16 \mathrm{~mm}$, a value similar to those presented in other studies which showed that these buccolingual canals have a length of $9.4-22.3 \mathrm{~mm}$, the average value being $15.85 \mathrm{~mm}[15,16]$.

Kang et al. (2014) [16], showed that there is no significant difference in the incidence of BMCs by age, but noted that the incidence was more common for patients in their third decade of life.

There are references in the literature indicating higher prevalence of BMCs among women, but gender-related differences may stem from the population being observed, rather than the type of radiographic examination performed $[5,6,13]$.

Given the data presented in the accessed references, regarding the prevalence of BMCs, we can say that there is no statistically significant difference related to sex or age.

CBCT is by far superior to conventional radiographs [17], and it is the most appropriate imaging method used for identifying the topography and confirming the presence of BMCs before surgery, so as to reduce or eliminate possible consecutive complications.

However, CBCT images do not provide data on the content of these accessory canals, on the branches from 
the inferior alveolar nerve and/or from the inferior alveolar artery [15].

In the future, the use of high-resolution magnetic resonance imaging (MRI) with the identification of blood vessels and nerves could hold out hope and constitute a promising step towards a complete and complex diagnosis of these accessory MCs [18].

The presence of the MC and accessory MCs located lingually in the posterior mandible requires special attention during all surgical procedures performed at this level, including procedures for harvesting mandibular grafts used for bone augmentation in implant dentistry [19-21].

When the presence of a BMC is identified, with possible origin located above the conventional anesthesia site commonly used (the mandibular foramen), Gow-Gates or Akinosi anesthesia techniques are recommended for inferior alveolar nerve block; however, these techniques must be performed only when traditional local anesthesia proves ineffective $[8,14,16]$. In the clinical case described, we opted for the Gow-Gates technique, in accordance with Lew \& Townsen (2006) observations, who showed that this anesthesia technique is more effective for blocking the accessory nerve branches, proximal to their place of origin [22].

In the case of mandibular fractures, the alignment of the fragments becomes considerably more difficult if there is a second canal containing a neurovascular bundle, located in a different plane [8].

In dentistry, any postoperative clinical situation with unexplained sensitivity disorders or the occurrence of bleeding in the posterior mandible can be associated with a radiographically invisible BMC containing neurovascular structures [15].

The practical relevance of this case study consists in drawing dentists' attention to the fact that the topographic anatomy of the MC is quite variable, an aspect that should not be underestimated.

\section{ㅁ Conclusions}

The presence of the $\mathrm{BMC}$ is considered a risk factor for patients; it must be carefully managed because it can contribute to the failure of inferior alveolar nerve block and to the emergence of neurovascular lesions during surgical procedures performed on the posterior mandible. A prior $\mathrm{CBCT}$ radiographic examination is required to identify such BMCs to prevent potential postoperative complications due to these anatomical variations.

\section{Conflict of interests}

The authors declare that they have no conflict of interests.

\section{Compliance with ethical standards}

Informed consent in written form was obtained from the patient for publishing this case report.

\section{References}

[1] Chávez-Lomeli ME, Mansilla Lory J, Pompa JA, Kjaer I. The human mandibular canal arises from three separate canals innervating different tooth groups. J Dent Res, 1996, 75(8): 1540-1544. https://doi.org/10.1177/00220345960750080401 PMID: 8906121
[2] Rashid SA, Ali J, Al-Nakib L. Identification of bifid mandibular canals among Iraqi subjects using panoramic imaging system. J Baghdad Coll Dent, 2011, 23(4):76-80. https://iasj.net/iasj ?func=fulltext\&ald $=1471$

[3] Mizbah K, Gerlach N, Maal TJ, Bergé SJ, Meijer GJ. The clinical relevance of bifid and trifid mandibular canals. Oral Maxillofac Surg, 2012, 16(1):147-151. https://doi.org/10.1007/s10006011-0278-5 PMID: 21698363 PMCID: PMC3294215

[4] von Arx T, Lozanoff S. Clinical oral anatomy: a comprehensive review for dental practitioners and researchers. Springer International Publishing, Switzerland, 2017, 342-350. https:// doi.org/10.1007/978-3-319-41993-0 https://link.springer.com/ book/10.1007/978-3-319-41993-0

[5] Sarkar S, Mondal S. Bifid mandibular canals: a case report and mini review. J Clin Adv Dent, 2020, 4(1):6-8. https://doi.org/ 10.29328/journal.jcad.1001015 https://www.heighpubs.org/hjd/ jcad-aid1015.php

[6] Kuribayashi A, Watanabe H, Imaizumi A, Tantanapornkul W, Katakami K, Kurabayashi T. Bifid mandibular canals: cone beam computed tomography evaluation. Dentomaxillofac Radiol, 2010, 39(4):235-239. https://doi.org/10.1259/dmfr/66254780 PMID: 20395465 PMCID: PMC3520225

[7] Worthington P. Injury to the inferior alveolar nerve during implant placement: a formula for protection of the patient and clinician. Int J Oral Maxillofac Implants, 2004, 19(5):731-734. PMID: 15508990

[8] Nithya J, Aswath N. Assessing the prevalence and morphological characteristics of bifid mandibular canal using cone-beam computed tomography - a retrospective cross-sectional study. J Clin Imaging Sci, 2020, 10:30. https://doi.org/10.25259/JCIS 672019 PMID: 32494509 PMCID: PMC7265462

[9] Nimigean $V(r e d)$. Anatomie clinică şi topografică a capului şi gâtului pentru medicina dentară - note de curs. Ed. Cermaprint, Bucureşti, 2014, 57, 58 (in Romanian).

[10] Sîrbu VD, Perlea P, Nimigean VR, Bădiţă DG, Şerban A, Nimigean $\mathrm{V}$. Morphological assessment of the mandibular canal trajectory in dentate subjects. Rom J Morphol Embryol, 2017, 58(4):1401-1408. PMID: 29556634

[11] Nimigean V, Sîrbu VD, Nimigean VR, Bădiţă DG, Poll A, Moraru SA, Păun DL. Morphological assessment of the mandibular canal trajectory in edentate subjects. Rom J Morphol Embryol, 2018, 59(1):235-242. PMID: 29940633

[12] Nimigean V, Nimigean VR, Sălăvăstru DI. A rare variant of internal anatomy of a third mandibular molar: a case report. Rom J Morphol Embryol, 2011, 52(2):691-693. PMID: 21655662

[13] Naitoh M, Hiraiwa Y, Aimiya H, Ariji E. Observation of bifid mandibular canal using cone-beam computerized tomography. Int J Oral Maxillofac Implants, 2009, 24(1):155-159. PMID: 19344041

[14] Okumuş Ö, Dumlu A. Prevalence of bifid mandibular canal according to gender, type and side. J Dent Sci, 2019, 14(2): 126-133. https://doi.org/10.1016/j.jds.2019.03.009 PMID: 31210887 PMCID: PMC6562102

[15] von Arx T, Bornstein MM. The bifid mandibular canal in threedimensional radiography: morphologic and quantitative characteristics. Swiss Dent J, 2021, 131(1):10-28. PMID: 33325209

[16] Kang JH, Lee KS, Oh MG, Choi HY, Lee SR, Oh SH, Choi YJ, Kim GT, Choi YS, Hwang EH. The incidence and configuration of the bifid mandibular canal in Koreans by using cone-beam computed tomography. Imaging Sci Dent, 2014, 44(1):53-60. https://doi.org/10.5624/isd.2014.44.1.53 PMID: 24701459 PMCID: PMC3972406

[17] Correr GM, Iwanko D, Leonardi DP, Ulbrich LM, Araújo MR, Deliberador TM. Classification of bifid mandibular canals using cone beam computed tomography. Braz Oral Res, 2013, 27(6): 510-516. https://doi.org/10.1590/S1806-83242013000600011 PMID: 24346049

[18] Krasny A, Krasny N, Prescher A. Anatomic variations of neural canal structures of the mandible observed by 3-Tesla magnetic resonance imaging. J Comput Assist Tomogr, 2012, 36(1):150153. https://doi.org/10.1097/RCT.0b013e3182436c6d PMID: 22261786

[19] Poll A, Minculescu CA, Nimigean VR, Bădiţă D, Bălăceanu RA, Păun DL, Moraru SA, Nimigean V. Experimental model for the study of autogenous mandibular bone grafts integration. Rom Biotechnol Lett, 2018, 23(3):13681-13689. https://www.erepository.org/rbl/vol.23/iss.3/16.pdf 
[20] Khoury F. Augmentation of the sinus floor with mandibular bone block and simultaneous implantation: a 6-year clinical investigation. Int J Oral Maxillofac Implants, 1999, 14(4):557564. PMID: 10453672

[21] Moraru SA, Cergan R, Bordea EN, Pellegrini A, Truţă RI Cismaş SC, Nimigean VR, Motaş N, Nimigean V. Clinical and medico-legal considerations on the vicinity of the third molar with the mandibular canal - literature review. Rom J Oral Rehabil, 2021, 13(3):123-131. https://www.rjor.ro/clinical-and- medico-legal-considerations-on-the-vicinity-of-the-third-molarwith-the-mandibular-canal-literature-review/

[22] Lew K, Townsen G. Failure to obtain adequate anaesthesia associated with a bifid mandibular canal: a case report. Aust Dent J, 2006, 51(1):86-90. https://doi.org/10.1111/j.1834-78 19.2006.tb00406.x PMID: 16669483

\section{Corresponding author}

Victor Nimigean, Professor, DMD, MD, PhD, Discipline of Anatomy, Faculty of Dental Medicine, Carol Davila University of Medicine and Pharmacy, 17-23 Plevnei Avenue, Sector 1, 010221 Bucharest, Romania; Phone +040722-368 849, e-mail: victornimigean@yahoo.com

Received: May 5, 2021

Accepted: December 27, 2021 